\title{
Structure-Activity Relationship and Design of an Antimutagen against the UV-Induced Mutation of Escherichia coli
}

\author{
Katsumi KaKinuma, ${ }^{*}$ Junpei KoIKe, ${ }^{*}$ Keiji IshibaShI, ${ }^{* *}$ \\ Wataru TAKAHASHI** and Hisashi TAKEI** \\ * Laboratory of Chemistry for Natural Products \\ and \\ ** Department of Life Chemistry, \\ Tokyo Institute of Technology, Nagatsuta, Midori-ku, Yokohama 227, Japan
}

Received August 27, 1985

\begin{abstract}
Structure-activity relationships of antimutagens were studied by assaying analogues and derivatives of $2(5 \mathrm{H})$ furanone designed on the basis of the structures of natual antimutagens by the method of observing UV-induced reversion of $E$. coli WP2 B/r uvr $A^{-} \operatorname{trp} E^{-}$. It is shown that an $\alpha, \beta$-unsaturated carbonyl system is required for antimutagenic activity. Further modification of $3(2 \mathrm{H})$ furanones resulted in the development of a highly potent antimutagen. The possibility that the antimutagenic effects may be due to alteration of proteins involved in the DNA repair system by trapping thiol groups is also discussed.
\end{abstract}

One major concern in human health is the undesirable effects of physical and chemical mutagens in the environment and their methods of control. Since the first observation of antimutagenic activity by Kada and Mochizuki, ${ }^{1)}$ we have been involved in a screening of antimutagenic factors from natural sources and have been able to isolate several compounds showing antimutagenic activity. ${ }^{2,3)}$ Although the mechanism of action of these antimutagenic factors is not clear at the moment, suggestions have been put forward that either error-prone DNA repair after exposuring cells to the mutagens is reduced or error-free recombinational repair may be enhanced. ${ }^{4 \sim 6)}$

To facilitate further precise biological studies on the molecular level, chemically stable and more effective antimutagens are badly needed. The development of a novel and stable antimutagen is one aspect of the present study. Since diterpenoid antimutagens had been reported to be also active against Ehrlich ascites carcinoma cells, ${ }^{7)}$ the modifications used in designing such antimutagens seem to be of interest for the development of new medicinally useful drugs as well.

We therefore undertook an analysis of the chemical structures of natural antimutagens that had been isolated by $\mathrm{us}^{2,3}$ as well as by others $^{8,9)}$ and concluded that a reactive $\alpha, \beta$ unsaturated carbonyl functionality was a common factor in compounds showing antimutagenic activity, at least in our bioassay system. This was briefly reported recently. ${ }^{10}$ We then designed potential antimutagenic compounds and examined their biological activities, this article describing these studies in detail.

\section{MATERIALS AND METHODS}

Antimutagenic assay. A preliminary qualitative evaluation of the antimutagenic activity of chemicals was conducted by using the paper disk-agar plate method and UV-irradiation as a mutagen as already described. ${ }^{1,2)} \mathrm{A}$ quantitative bioassay was carried out according to the soft agar method described previously. ${ }^{1,3,9)}$ In brief, a chemical dissolved and diluted to an appropriate concentration in dimethyl sulfoxide, together with either a UV-treated or untreated cell suspension of Escherichia coli WP2 B/r uvr $A^{-} \operatorname{trp} E^{-}$, were mixed in a soft agar medium consisting of $0.8 \% \mathrm{NaCl}$ and agar $0.6 \%$ agar (Difco) in distilled water and spread onto the MB agar plate. After 3 days 
incubation at $37^{\circ} \mathrm{C}$, the $\operatorname{Trp}^{+}$revertant colonies and $\operatorname{Trp}$ viable cell colonies were counted. Mutation frequencies and viable cell counts were plotted against dosage as described previously. ${ }^{1,3,9)}$ The specific activities of chemicals are expressed in $\mathrm{AD}_{50}$ value ( $A$ ntimutagenic $D$ ose), the dose which reduces the mutation frequency to $50 \%$ of the control, as introduced by Komura et al. ${ }^{9)}$ these $\mathrm{AD}_{50}$ values being estimated from the mutation frequency plots.

Synthesis of potential antimutagenic compounds. All the compounds tested in the present study were prepared by us. 5-Methylene-2(5H)furanone (protoanemonin) was freshly prepared from levulinic acid by a method reported by Grundmann. ${ }^{11)}$ Various alkylidene-2 $(5 H)$ furanones were synthesized through a method developed by Asaoka and Takei. ${ }^{12)}$ 3-Methyl- and 4-methyl-5-methylene$2(5 H)$ furanones were prepared by a modified method of Young et al. ${ }^{13)}$ 4,5-Dihydro-5-methylene-2(3H)furanone,${ }^{14)}$ ( \pm$)-5$-methyl-2(5H)furanone, ${ }^{15)}$ 4-vinyl-2$(5 H)$ furanone, ${ }^{16)} \quad 4,5$-dihydro-3-methylene-2 $(3 H)$ furanone (Tulipalin $\mathrm{A})^{17)}$ and 4-oxo-2-pentenoic acid ${ }^{18)}$ were respectively prepared according to the literature procedures. $( \pm)$-Avenaciolide was a stock sample prepared previously by Takei et al. ${ }^{19)}$ Substituted $3(2 H)$ furanones were prepared either by a method of Smith, III, ${ }^{20)}$ or via the 1,3-dipolar addition of nitrile oxides, which will be reported elsewhere.

\section{RESULTS AND DISCUSSION}

As shown in Fig. 1, a close examination of the structures of naturally occurring organic antimutagens obtained so far revealed a conjugated $\alpha, \beta$-unsaturated carbonyl system as a common functional and structural feature. This prompted us to choose the structure of 5methylene-2 $(5 H)$ furanone (protoanemonin) (1) as a basic model framework for further modification to study the structure-activity relationships.

Analogues and related compounds of $\mathbf{1}$, the structures of which are shown in Fig. 2, were first examined by a disk assay (Table 1). Among the tested compounds, 5-acetoxy-5methyl-2(5H)furanone (3) showed the highest activity. This seemed reasonable because this compound is a potent precursor of $\mathbf{1}$. Although the activity was not as high, 5methyl-2(5H)furanone (2), which contains an $\alpha, \beta$-unsaturated carbonyl system, was active. A stereoisomeric mixture of 5-ethylidene$2(5 H)$ furanones (5 and $\mathbf{6})$ was modestly active

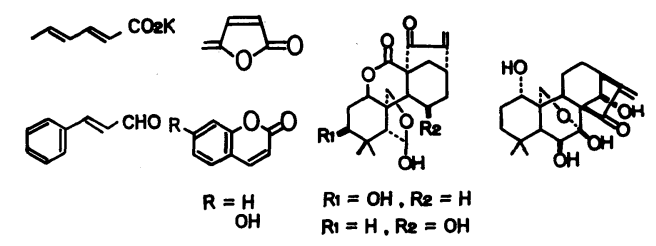

FIG. 1. Naturally Occurring Antimutagens.

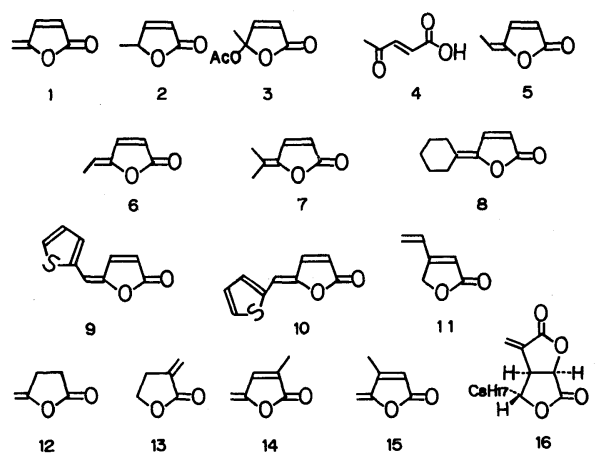

FIG. 2. Derivatives and Related Compounds of 5Methylene-2 $(5 H)$ furanone.

at a dosage of $100 \mu \mathrm{g} /$ disk, while 5-isopropylidene- and 5-cyclohexylidene derivatives (7 and 8) were weakly active at $500 \mu \mathrm{g} /$ disk. Thienyl methylidene derivatives (9 and 10) were inactive, and 4-oxo-2-pentenoic acid (4). was active. This may be either because of its own conjugated system or because of its partial transformation into $\mathbf{1}$.

The functional group requirements were further tested by using different compounds. A nonconjugated 4,5-dihydro-5-methylene-2$(3 H)$ furanone $(12)$ was inactive for both assays. As shown in Fig. 3, the mutation frequency and the viable cell count were almost unaffected over a wide dose range. Although the simplest unsubstituted 2(5H)furanone was not tested, these results were significant and it appears that an $\alpha, \beta$-unsaturated carbonyl system is required for antimutagenic activity at least as measured by the present assay method. 4-Vinyl-2(5H)furanone (11) was more active $\left(\mathrm{AD}_{50}: 95 \mu \mathrm{g}\right.$, Table II). In this case, viable cell counts were unchanged within the dose range tested, i.e., there was no bactericidal effect, and the mutation frequency showed good dose response 
Table I. Antimutagenic Activities of $2(5 H)$ Furanone Derivatives Determined By the Qualitative Paper Disk Method

\begin{tabular}{rccccc}
\hline Compound & $100 \mu \mathrm{g} /$ disk & $500 \mu \mathrm{g} /$ disk & Compound & $100 \mu \mathrm{g} /$ disk & $500 \mu \mathrm{g} /$ disk \\
\hline $\mathbf{1}$ & +++ & +++ & $\mathbf{5 + 6}$ & + & ++ \\
$\mathbf{1 4}$ & + & ++ & 7 & \pm & + \\
$\mathbf{2}$ & \pm & + & $\mathbf{8}$ & \pm & + \\
$\mathbf{3}$ & ++ & +++ & $\mathbf{9}$ & - & \pm \\
$\mathbf{4}$ & + & ++ & $\mathbf{1 0}$ & - & \pm \\
\hline
\end{tabular}

+++ , highly active; ++ , active; + , slightly active; \pm , almost inactive; - , inactive.

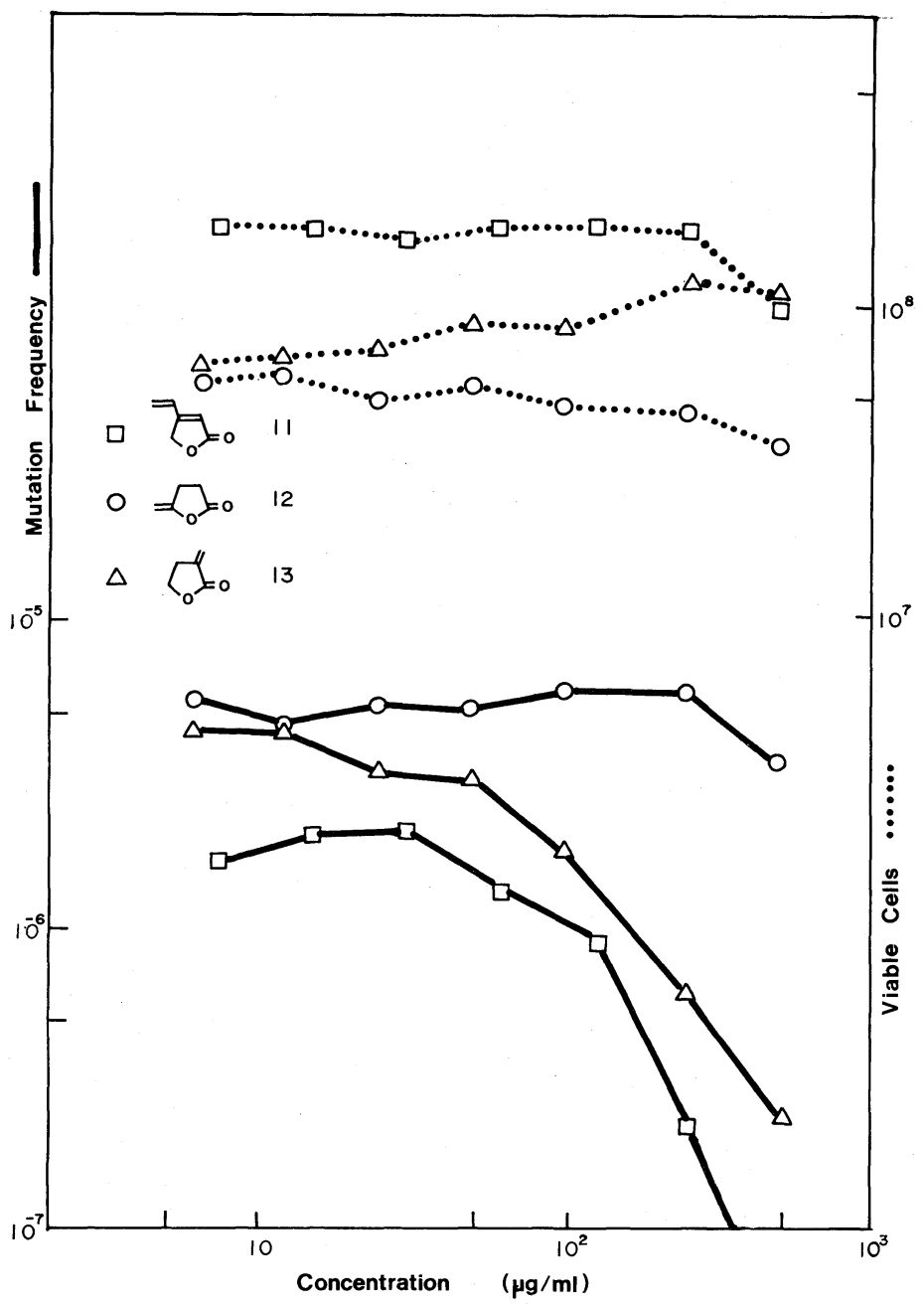

Frg. 3. Antimutagenic Activities of 2(5H)Furanone Derivatives Determined by the Quantitative Soft Agar Method.

at $35 \mu \mathrm{g} / \mathrm{ml}$ and higher. A different $\alpha, \beta$-unsaturated- $\gamma$-lactone, 4,5-dihydro-3-methylene$2(3 H)$ furanone (13), which is known as a naturally occurring tulipalin $\mathrm{A}$, also showed similar activity $\left(\mathrm{AD}_{50}: 110 \mu \mathrm{g} / \mathrm{ml}\right)$ to that of 11. It was of interest to note that, for this compound, the viable cell counts showed a slight increase along with dosage. (土)- 
Table II. Specific Activities of Synthetic Antimutagens ExPressed BY the $\mathrm{AD}_{50}$ Values Introduced by Minakata et al.

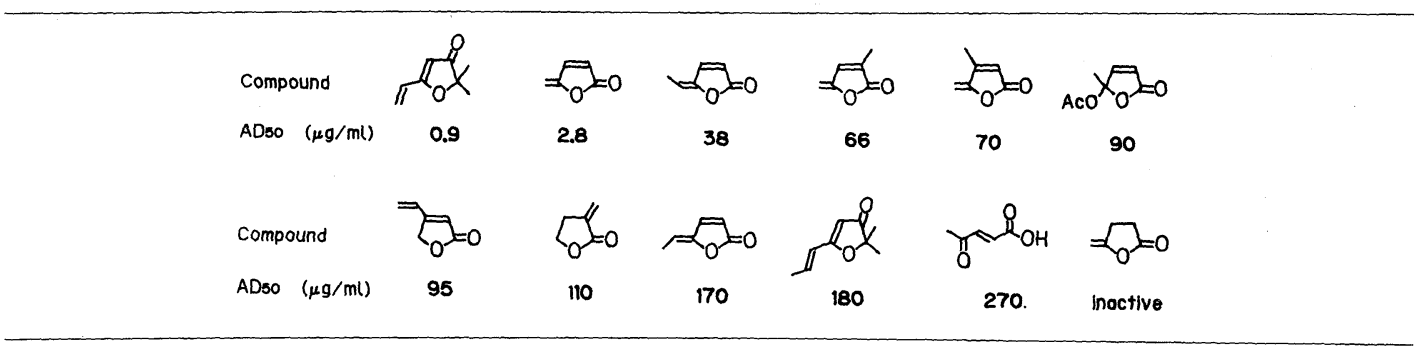

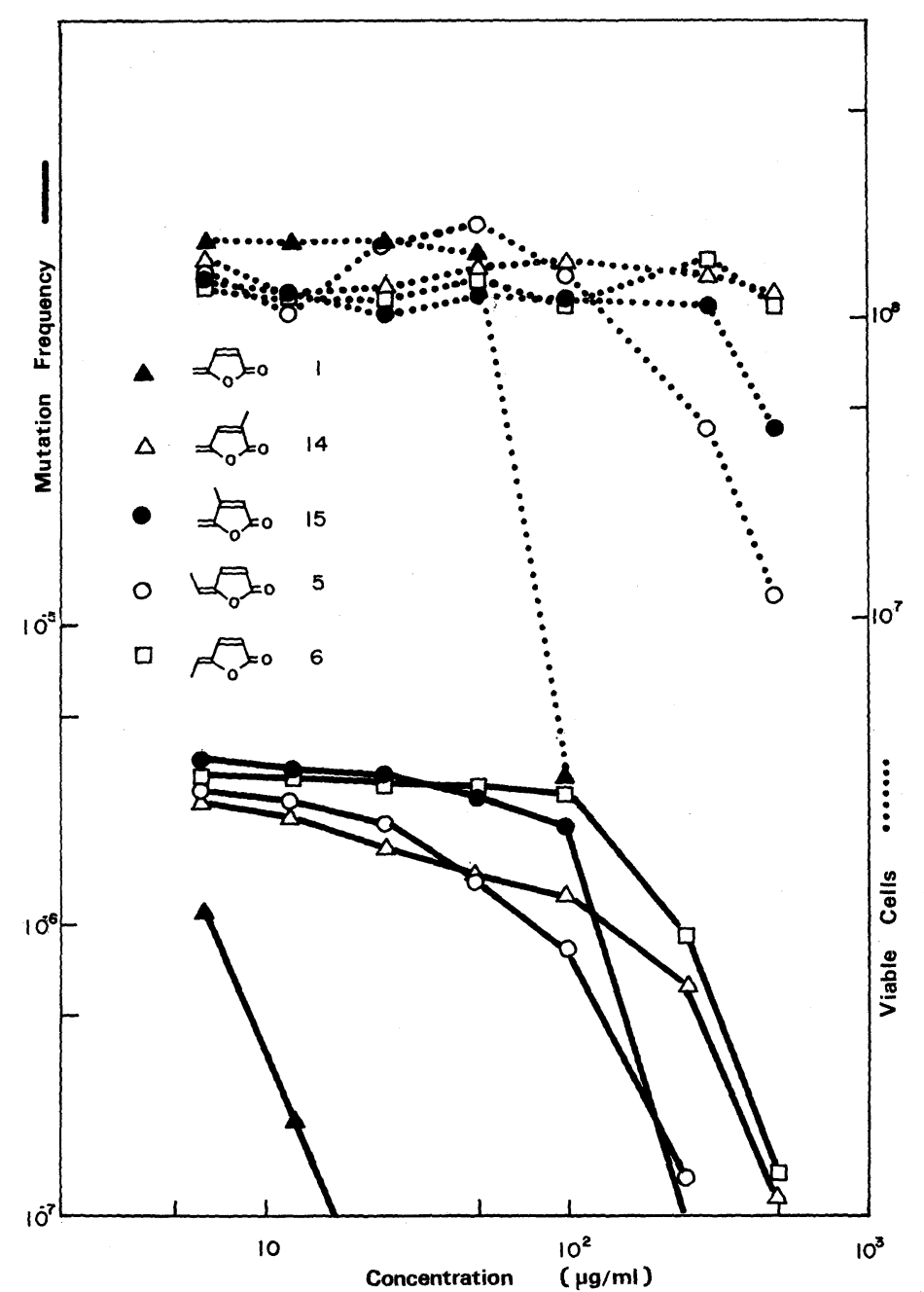

Fig. 4. Comparison of Antimutagenic Activities of the Methyl Substituted 5-Methylene-2(5H)furanones.

Avenaciolide (16), which contains a similar $\alpha$ methylene- $\gamma$-butyrolactone system, showed no antimutagenic activity (data not shown), probably because of the bulky peripheral structure.
The effects of methyl group substitution upon the protoanemonin structure were then tested by the soft agar method (Fig. 4). Although the $\mathrm{AD}_{50}$ value of the $(E)-5$ ethylidene-2(5H)furanone 5 was $38 \mu \mathrm{g} / \mathrm{ml}$, the 
mutation frequency and the viable cell counts were parallel over the dose range used, and as a result, the bactericidal effect and the antimutagenic activity could not be differentiated. On the other hand, the $(Z)$ isomer 6 was judged to be slightly less active $\left(\mathrm{AD}_{50}: 170 \mu \mathrm{g} / \mathrm{ml}\right)$, but showed no appreciable bactericidal effect.

3-Methyl- and 4-methyl substituted 2(5H)furanones (14 and 15), were also tested by both a qualitative and quantitative assay, and their activities were similarly moderate; $\mathrm{AD}_{50}$ of the former was $66 \mu \mathrm{g} / \mathrm{ml}$ and that of the latter was $70 \mu \mathrm{g} / \mathrm{ml}$.

In summary, among those $2(5 H)$ furanone derivatives tested so far, protoanemonin (1) showed the highest activity and 4-vinyl2(5H)furanone (11) was the second highest. Substituted 2(5H)furanones were less active. It seems likely then that the terminal carbon of the conjugated system should be unsubstituted and sterically unhindered for higher activity. This trend was also observed in the case of isomeric $3(2 H)$ furanones that are subsequently discussed.

Attentions were then turned from $2(5 H)$ furanones to isomeric $3(2 H)$ furanone structures, since the $\alpha, \beta$-unsaturated carbonyl system is found in the structures of bullatenone, geiparvarin and jatrophone (Fig. 5), which had been isolated from natural sources and were reported to have antitumor activities. ${ }^{21)}$ All of these natural compounds include rather complex structural units and it seemed difficult to specify the structural units responsible for their biological activities. In this study, however, we focussed on the antimutagenic activity of the $3(2 \mathrm{H})$ furanone structure, i.e. bullatenone (17), 2,2-dimethyl$3(2 H)$ furanone $(\mathbf{1 8}),(E)-5$-(prop-1-enyl)-3(2H)furanone (19) and 5-vinyl-3(2H)furanone (20) were synthesized (Fig. 6) and assayed by the soft agar method as already described. The first two compounds were shown to be inactive; however, 19 was slightly active, $\mathrm{AD}_{50}$ of $180 \mu \mathrm{g} / \mathrm{ml}$, about half as active as 4vinyl-2 $(5 H)$ furanone $(\mathbf{1 1})$. Of significance was that 5-vinyl-3(2H)furanone (20) was found

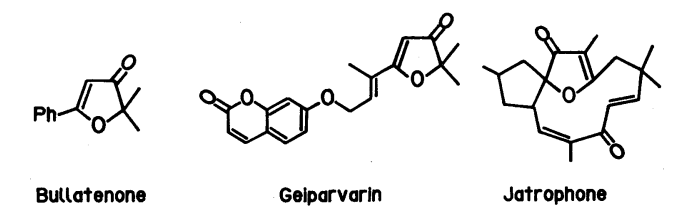

FIG. 5. Naturally Occurring 3(2H)Furanone Compounds.

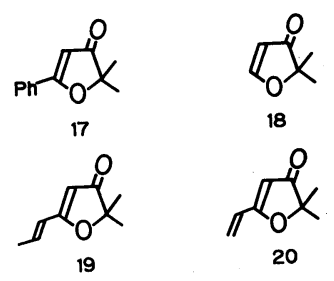

to be the most active compound so far tested (Table II). The $\mathrm{AD}_{50}$ was $0.9 \mu \mathrm{g} / \mathrm{ml}$ which was $c a .3$ times as active as protoanemonin (1, $\mathrm{AD}_{50}$ of $2.8 \mu \mathrm{g} / \mathrm{ml}$ ). Furthermore this compound was more stable and easy to handle. Again, in the case of $3(2 H)$ furanones, the terminal methylene carbon of the conjugated carbonyl system should be unsubstituted for high activity.

Based on the results already described above, the conjugated carbonyl system of the antimutagenic compounds seems to react at the terminal carbon with some reactants during the development of the antimutagenic action. One of the most likely candidates for the reactant is thiol functionalities, since the above-mentioned conjugated dienone systems can be good Michael acceptors and a thiol goups is known to be a good nucleophile in living systems. These considerations are supported by the fact that tulipalin A (13) was active in this antimutagenic assay, because tulipalin $\mathrm{A}$ is among the naturally occurring antitumoric $\alpha$-methylene- $\gamma$-lactones and is suggested to show its antitumor activity by trapping thiol goups of enzymes involved in the nucleic acid replication. ${ }^{22)} \mathrm{A}$ well-known thiol trapping agent, $N$-ethylmaleimide, was also assayed in this study, but it showed high bactericidal activity and its antimutagenic activity could not be differentiated within the 
dose range tested (data not shown). A preliminary experiment was undertaken to see the reactivity of 5-vinyl-3(2H)furanone, i.e., the vinyl proton signals were monitored on a ${ }^{1} \mathrm{H}-\mathrm{NMR}$ spectrum from time to time in the presence of propanethiol in a $\mathrm{CD}_{3} \mathrm{OD}$ solvent without any catalyst, and disappearance of these signals was observed within $20 \mathrm{~min}$. Therefore, although structurally unusual amino acids of plant origin have recently been noted as antimutagenic against the spontaneous mutation of Salmonella typhimurium TA $100^{23)}$ and some tea catechins were reported to be active against the spontaneous mutation of Bacillus subtilis NIG1125,24) it is likely at the moment that the natural as well as the above-menthioned synthetic antimutagens exhibit their activities by trapping thiol groups of the cysteinyl residues of appropriate proteins. Previously, the reaction mechanism of these antimutagens was suggested to be correction of the error-prone SOS response induced by UV-irradiation ${ }^{5)}$ and it is known that various proteins play important roles in the SOS repair system. On the other hand, it has recently been suggested that the antimutagenic effect of cinnamaldehyde on chemically induced mutagenesis is due to the enhancement of an error-free recombinational repair system. ${ }^{25)}$

While research in this field has been advancing, precise understanding of mutagenesis and antimutagenic action seems to require further investigations on the molecular level, and the novel antimutagens disclosed here may be useful for such studies.

Acknowledgments. The authors wish to express their deep appreciation to Professor N. Ikekawa of the Department of Chemistry, Tokyo Institute of Technology, and Professor Tsuneo Kada of the National Institute of Genetics for their kind advice.

\section{REFERENCES AND NOTES}

1) T. Kada and H. Mochizuki, J. Radia. Res., 22, 297 (1981).

2) K. Kakinuma, Y. Okada, N. Ikekawa, T. Kada and
M. Nomoto, Agric. Biol. Chem., 48, 1647 (1984).

3) K. Kakinuma, J. Koike, K. Kotani, N. Ikekawa, T. Kada and M. Nomoto, Agric. Biol. Chem., 48, 1905 (1984).

4) T. Kada and N. Kanematsu, Proc. Japan Acad., 54, 234 (1978).

5) T. Inoue, Y. Ohta, Y. Sadaie and T. Kada, Mutation Res., 91, 41 (1981).

6) T. Ohta, K. Watanabe, M. Moriya, Y. Shirasu and T. Kada, Mutation Res., 107, 219 (1983).

7) E. Fujita, Y. Nagao, M. Node, K. Kaneko, S. Nakazawa and H. Kuroda, Experientia, 32, 203 (1976).

8) T. Ohta, K. Watanabe, M. Moriya, Y. Shirasu and T. Kada, Mutation Res., 107, 135 (1983).

9) H. Minakata, H. Komura, K. Nakanishi and T. Kada, Mutation Res., 116, 317 (1983).

10) a) K. Kakinuma, J. Koike, K. Ishibashi, W. Takahashi, H. Takei, N. Ikekawa and T. Kada, Abstracts of Papers, the Annual Meeting of the Agricultural Chemical Society of Japan, 2M-27, June 1985 , p. 568; b) K. Ishibashi, W. Takahashi, H. Takei, K. Kakinuma, J. Koike and N. Ikekawa, ibid., 2M28, June 1985, p. 568.

11) C. Grundman and E. Kober, J. Am. Chem. Soc., 77, 2332 (1955).

12) M. Asaoka, N. Yanagida, K. Ishibashi and H. Takei, Tetrahedron Lett., 22, 4269 (1981).

13) J. B. Jones and J. M. Young, J. Med. Chem., 11, 1176 (1968).

14) 4,5-Dihydro-5-methylene-2(3H)furanone was synthesized through the iodolactonization of 4pentenoic acid, and followed by treatment with DBU in dry benzene.

15) ( \pm )-5-Methyl-2(5H)furanone was prepared by isomerization of $\alpha$-angelicalactone using $\mathrm{Et}_{3} \mathrm{~N}$ in dichloroethane.

16) F. Kido, K. Tsutsumi, R. Murata and A. Yoshikoshi, J. Am. Chem. Soc., 101, 6420 (1979).

17) A. D. Harmon and C. R. Hutchinson, J. Org. Chem., 39, 1854 (1974).

18) M. Asaoka, N. Yanagida, N. Sugimura and H. Takei, Bull. Chem. Soc. Jpn., 53, 1061 (1980).

19) H. Takei, Y. Fukuda, T. Taguchi, T. Kawara, H. Mizutani and T. Mukuta, Chem. Lett., 1311 (1980).

20) A. B. Smith III, P. A. Levenberg, P. J. Jerris, R. M. Scaborough Jr. and P. M. Wovkulich, J. Am. Chem. Soc., 103, 1501 (1981).

21) a) K. Padmawinata, Acta Pharm., 41, 1 (1973) [C. A., 79, $75897 n$ (1973)]; b) S. M. Kupchan, C. W. Siegel, M. J. Matz, J. A. Saenz Renauld, R. C. Haltiwamger and R. F. Bryan, J. Am. Chem. Soc., 92, 4477 (1970).

22) J. M. Cassady and M. Suffness, "Antitumor Agents based on Natural Product Models," ed. by J. M. Cassady and J. D. Douros, Academic Press Inc., New York, 1980, p. 201.

23) H. Komura, personal communication. 
24) T. Kada, Y. Hara and S. Matsuzaki, Abstracts of Papers, the Annual Meeting of the Agricultural Chemical Society of Japan, 3V-20, March 1984, p.
637.

25) T. Ohta, K. Watanabe, M. Moriya, Y. Shirasu and

T. Kada, Mol. Gen. Genet., 192, 309 (1983). 